\title{
Semisolid Processing Characteristics of AM Series Mg Alloys by Rheo-diecasting
}

\begin{abstract}
S. Ji, Ma Qian, and Z. Fan
An investigation has been made into the solidification behaviour and microstructural evolution of AM50, AM70 and AM90 alloys during rheo-diecasting, their processibility, and the resulting mechanical properties. It was found that, solidification of AM series alloys under intensive melt shearing in the unique twin-screw slurry maker during rheo-diecasting, gave rise to numerous spheroidal primary magnesium particles that were uniformly present in the microstructure. As a result, the network of the $\beta-\mathrm{Mg}_{17} \mathrm{Al}_{12}$ phase was consistently interrupted by these spheroidal and ductile particles. Such a microstructure reduced the obstacle of deformation and the harmfulness of the $\beta$ $\mathrm{Mg}_{17} \mathrm{Al}_{12}$ network on ductility, and therefore improved the ductility of rheo-diecast AM alloys. It was

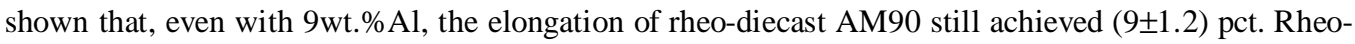
diecasting thus provides an attractive processing route for upgrading the alloy specification of AM series alloys by increasing the Al content while ensuring ductility. Assessment of the processibility of $\mathrm{AM}$ series alloys for semisolid processing showed that, high Al content AM series alloys are more suitable for rheo-diecasting than low Al content alloys, because of the lower sensitivity of solid fraction to temperature, the lower liquidus temperature, and the smaller interval between the semisolid processing temperature and the complete solidification temperature.
\end{abstract}

\section{INTRODUCTION}

THE development of the semisolid metal (SSM) processing technique was initiated immediately following the discovery of the pseudoplastic and thixotropic properties of metallic alloys at temperatures between the liquidus and the solidus ${ }^{[1]}$. Through more than three decades of development SSM processing has been successfully established as a unique technique for production of metallic components with high integrity and improved mechanical properties ${ }^{[2,3]}$. One of the latest technical developments in SSM processing is the rheo-diecasting (RDC) process ${ }^{[4,5]}$, where high quality SSM slurry containing fine and spheroidal primary particles is produced via a twin-screw shearing mechanism, and subsequently cast for near-net shape forming by conventional high pressure die casting (HPDC). The technique is applicable to a wide variety of metallic materials, particularly light metals.

Owing to their high strength-to-weight ratio, ease of casting and superior machinability, magnesium alloys are receiving increased attention as structural materials. AM series alloys are among the most widely used magnesium alloys because of their excellent combination of ductility and strength. In these alloys, aluminium ( $\mathrm{Al})$ and manganese $(\mathrm{Mn})$ are two primary alloying elements. Al improves strength and hardness, and lowers the melting point for easy casting, and $\mathrm{Mn}$ is mainly for improving the seawater corrosion resistance, by removing iron and possibly other heavy metal elements into relatively harmless intermetallic

S. JI, Chief Engineer, MA QIAN, Lecturer, and Z. FAN, Professor, are with the Brunel Centre for Advanced Solidification Technology (BCAST), Brunel University, Uxbridge, Middlesex, UB8 3PH, United Kingdom.

Contact e-mail: Shouxun.ji@brunel.ac.uk

Manuscript submitted July 22, 2005. compounds ${ }^{[6]}$. It has been found that an $\mathrm{Al}$ content of $6 \mathrm{wt} . \%$ gives the optimum combination of ductility and strength to $\mathrm{Mg}$-Al based alloys when processed by conventional means ${ }^{[6]}$. Further increasing the $\mathrm{Al}$ content will degrade the elongation to failure of $\mathrm{Mg}$-Al based alloys. This has been well demonstrated for $\mathrm{AZ}$ series $\mathrm{Mg}$ alloys. For instance, the elongation of the HPDC processed AZ91D (Mg-9\%Al-1\%Zn) alloy is typically just around $3 \%{ }^{[6]}$. The widely used HPDC processed AM50 and AM60B are based on this principle. No higher aluminium content AM alloys have been developed for HPDC yet.

However, how the $\mathrm{Al}$ content affects the microstructure and mechanical properties of SSM processed AM series alloys is not clear. In fact, there have been contradictory reports about the advantages of SSM processing over HPDC for AM alloys. Koren et al. ${ }^{[7]}$ conducted both rheocasting and thixocasting trials on AM50 under different casting conditions, and concluded that no obvious advantages were observed for SSM processing of AM50, in terms of both rheological and mechanical properties. On the other hand, improved mechanical properties have been reported for thixomoulded AM50 and AM60B alloys. The ultimate tensile strength and elongation of thixomoulded samples of AM50 achieved $268.7 \mathrm{MPa}$ and $20 \%{ }^{[6]}$, and those of thixomoulded samples of AM60B achieved $255 \mathrm{MPa}$ and $11 \%{ }^{[8]}$, demonstrating very encouraging improvements in mechanical properties. Recent work by Czerwinski ${ }^{[9]}$ showed that thixomoulding of a $\mathrm{Mg}$ 6wt.\%Al alloy at semisolid temperatures exhibited a combination of strength and elongation superior to its counterparts produced from super-heated liquid. Therefore, a detailed investigation into the technical potential of SSM processing for AM series alloys is necessary for the further development and broader applications of these alloys. This requires a good understanding of the solidification behaviour and microstructural characteristics of these alloys in the newly developed twin-screw rheo-diecasting process. In addition, the SSM processibility of AM series alloys is also an important issue that needs to be addressed 
when considering semisolid processing. This is because for a given solid fraction of semisolid slurry, if the processing window is narrow, the suitability of the alloy for SSM processing will be much limited, even though the resulting mechanical properties are encouraging. Currently there is little information available in this regard for AM series alloys.

This work is conducted to address these concerns for SSM processing of AM series alloys in the newly developed rheo-diecasting process ${ }^{[4,5]}$. The microstructural characteristics of AM series alloys are examined at different stages of solidification during rheo-diecasting. A detailed assessment is made of the technical potential of SSM processing in improving the mechanical properties of AM series alloys; the SSM processibility of AM series alloys; and the influence of the $\mathrm{Al}$ content on the processibility, microstructure and mechanical properties of AM series alloys.

\section{EXPERIMENTAL PROCEDURE}

Three different AM alloys, AM50, AM70 and AM90, were selected for rheo-diecasting. Commercial grade AM50 ingots were used as the base alloy material for semisolid processing of all three alloys, where AM70 and AM90 were made by further alloying AM50 with commercial purity Al. Table I lists the composition of each alloy obtained from optical mass spectroscopy, in which four spark analyses were performed and the average was taken as the chemical composition. Melting was performed in a steel crucible at $720^{\circ} \mathrm{C}$ for $\mathrm{AM} 50$, $700^{\circ} \mathrm{C}$ for $\mathrm{AM} 70$, and $680^{\circ} \mathrm{C}$ for $\mathrm{AM} 90$. The melt was protected by $0.4 \% \mathrm{SF}_{6}$ in $\mathrm{N}_{2}$.

The rheo-diecasting machine consists of a twin-screw slurry maker with $1 \mathrm{~kg}$ capacity of molten magnesium and a 280t cold chamber diecasting machine. A detailed description of the rheo-diecasting process and equipment can be found in Ref. [10]. Fig. 1 shows schematically the rheo-diecasting equipment used in current investigation. It consists of two basic functional units, a twin-screw slurry maker and a standard cold chamber HPDC machine. The twin-screw slurry maker has a pair of screws rotating inside a barrel. The screws have specially designed profiles to achieve co-rotating, fully intermeshing and self-wiping. The fluid flow inside the slurry maker is characterized by high shear rate and high intensity of turbulence. The basic function of twin-screw slurry maker is to convert the liquid alloy into high

Table I. Chemical compositions (wt.\%) of AM series alloys in ingots and rheo-diecast samples, analysed by optical mass spectroscopy.

\begin{tabular}{ccccccc}
\hline & \multicolumn{2}{c}{ AM50 } & \multicolumn{2}{c}{ AM70 } & \multicolumn{2}{c}{ AM90 } \\
\cline { 2 - 7 } & Ingot & $\begin{array}{c}\text { Rheo- } \\
\text { diecast }\end{array}$ & Ingot & $\begin{array}{c}\text { Rheo- } \\
\text { diecast }\end{array}$ & Ingot & $\begin{array}{c}\text { Rheo- } \\
\text { diecast }\end{array}$ \\
\hline $\mathrm{Al}$ & 4.749 & 4.587 & 7.191 & 7.041 & 9.038 & 8.806 \\
$\mathrm{Mn}$ & 0.411 & 0.381 & 0.360 & 0.353 & 0.382 & 0.368 \\
$\mathrm{Zn}$ & 0.047 & 0.049 & 0.051 & 0.045 & 0.042 & 0.040 \\
$\mathrm{Si}$ & 0.040 & 0.040 & 0.040 & 0.039 & 0.040 & 0.040 \\
$\mathrm{Cu}$ & $<0.005$ & $<0.005$ & 0.018 & 0.017 & 0.019 & 0.019 \\
$\mathrm{Be}$ & 0.0008 & 0.0007 & 0.006 & 0.006 & 0.006 & 0.006 \\
$\mathrm{Fe}$ & 0.001 & 0.001 & 0.003 & 0.003 & 0.003 & 0.003 \\
$\mathrm{Ni}$ & $<0.002$ & $<0.002$ & $<0.002$ & $<0.002$ & $<0.002$ & $<0.002$ \\
$\mathrm{Mg}$ & Balance & Balance & Balance & Balance & Balance & Balance \\
\hline
\end{tabular}

quality semisolid slurry through solidification of the liquid alloys under high shear rate and high intensity of turbulence. The accurate proportional-integral-differential (PID) control within the twin-screw slurry maker ensures the temperature variation within $1{ }^{\circ} \mathrm{C}$. The twin-screw slurry maker works in a batch manner, typically providing semisolid slurry within 30s. During rheo-diecasting, a predetermined dose of melt is poured into the twin-screw slurry maker while both screws are rotating at a fixed speed and at a temperature in the semisolid range of the experimental alloy. The effects of shearing parameters on the resulting semisolid structures have been investigated in detail on AZ91 ${ }^{[11]}$. On the basis of these studies, the shearing parameters were chosen to be 800 revolutions per minute (rpm) and 30 seconds for all experiments in this study. The twin-screw slurry maker was set at temperatures to create different solid fractions of the experimental alloys. During experiments, after the melt was converted into semisolid slurry under intensive shearing within 30 s, the semisolid slurry was subsequently released into the shot sleeve of the HPDC machine for the final casting. Samples for tensile tests were cast using a specially designed die, which allowed casting four ASTM standard tensile samples with $6.0 \mathrm{~mm}$ in diameter for each shot. The die temperature was set at $235^{\circ} \mathrm{C}$ in all shots.

The tensile tests were conducted following ASTM standard B557, using an Instron 5500 Universal Electromechanical Testing Systems equipped with a Bluehill software and a $\pm 50 \mathrm{kN}$ load cell. All tensile tests were performed at ambient temperature $\left(\sim 25^{\circ} \mathrm{C}\right)$ using ascast samples. No solution treatment was applied to the samples. The gauge length of the extensometer was $50 \mathrm{~mm}$ and the ramp rate for extension was $1 \mathrm{~mm} / \mathrm{min}$. Each set of data reported is based on the properties obtained from 1520 samples (without showing obvious casting defects on the fractured surfaces).

The microstructure of each alloy was examined using a Zeiss optical microscope with quantitative metallography, and a JEOL JXA-840A scanning electron microscope (SEM), equipped with energy dispersive spectroscopy (EDS). All metallographic samples were prepared by the standard technique of grinding with $\mathrm{SiC}$ abrasive paper and final polishing with an $\mathrm{Al}_{3} \mathrm{O}_{2}$ suspension solution, followed by etching in a 2 vol.\% Nital solution. The particle size, shape factor, and volume (area) fraction of the solid phase were measured using an AxioVision 4.3 Quantimet digital

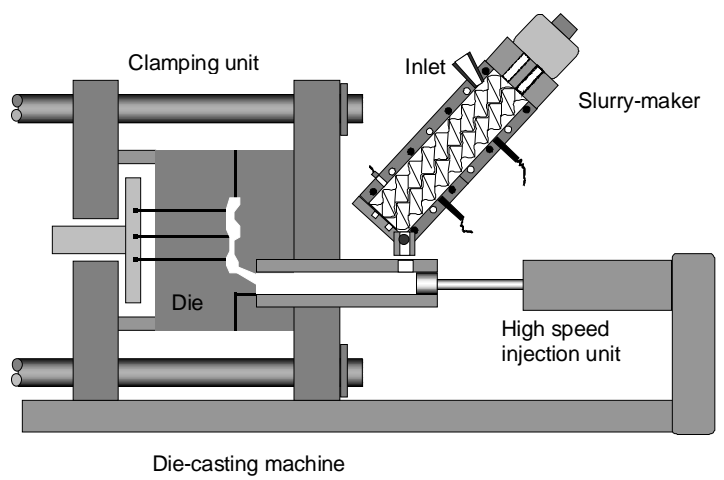

Fig. 1--A schematic illustration of the rheo-diecasting equipment, consisting of two function units: the twin-screw slurry maker and a conventional cold chamber HPDC machine.

image analysis system. Five different fields of view, with 
each being approximately $9,400 \mu \mathrm{m}^{2}$ in area, were analysed for each specimen and the average was taken as the measurement. The shape factor $F$ is defined as $F=4 \pi A / P^{2}$, where $A$ and $P$ are the area and the peripheral length of the particle, respectively. The quantitative EDS analysis was performed under the $15 \mathrm{kV}$ accelerating voltage, using pure copper as the standards. The accuracy was within $0.1 \%$. To minimise the influence from the interaction volume, five point analyses on selected large particles were conducted for each phase and the average was taken as the measurement. The standard deviations for the aluminium contents in the primary phase obtained from the RDC processed samples of AM50, AM70 and AM90 were $0.13 \%, 0.07 \%$ and $0.24 \%$, respectively.

\section{RESULTS}

\section{A. Microstructure of rheo-diecast AM series alloys}

The solidification occurring in the rheo-diecasting process is characterised by two stages ${ }^{[11]}$. The first is the nucleation and growth of the primary $\alpha-\mathrm{Mg}$ phase under intensive melt shearing inside the twin-screw slurry maker, which is defined as primary solidification. The second is the subsequent solidification of the remaining liquid in the semisolid slurry in the shot sleeve and the die cavity, which is referred to secondary solidification. Fig. 2 shows a typical view of the microstructure of AM series alloys produced by rheo-diecasting. The microstructures were characterised by fine and spheroidal particles that were uniformly distributed in the matrix. The spheroidal particles were the primary $\mathrm{Mg}$ phase (denoted $\alpha_{1}$ ) formed during primary solidification. Figs. 3 (a) and (b) show the average particle size and the shape factor, respectively, for the primary $\alpha_{1}-\mathrm{Mg}$ particles corresponding to various volume fractions, i.e. different processing temperatures. The primary $\alpha_{1}-\mathrm{Mg}$ particles exhibited similar sizes and morphology at various volume fractions for each alloy. The particle sizes were generally at an order of $40 \mu \mathrm{m}$ and the shape factors were around 0.75. However, changing the processing temperatures could significantly change the solid fractions of the primary phase. The solid fraction of the primary $\alpha_{1}-\mathrm{Mg}$ particles showed an obvious increase with a decrease in shearing temperature for each alloy, where the shearing temperatures employed were lower for alloys containing higher $\mathrm{Al}$ due to the influence of the Al content on the liquidus. For a given solid fraction of the primary $\alpha_{1}-\mathrm{Mg}$ particles, the difference in the shearing temperature between AM50 and AM90 could be as large as $20^{\circ} \mathrm{C}$.

Table II gives the EDS analytical results of the primary $\alpha_{1}-\mathrm{Mg}$ particles in rheo-diecast AM series alloys at the volume fraction $\mathrm{f}_{\mathrm{s}}=0.3$ and the results obtained from CALPHAD predictions. The $\mathrm{Al}$ content in the primary $\alpha_{1}-\mathrm{Mg}$ particles increased with increasing $\mathrm{Al}$ content in each alloy. As can be seen, the measured Al contents in the primary $\alpha_{1}-\mathrm{Mg}$ particles are fairly close to those predicted by the CALPHAD approach. Meanwhile, the measured solid fraction was in good agreement with the calculated solid fraction using

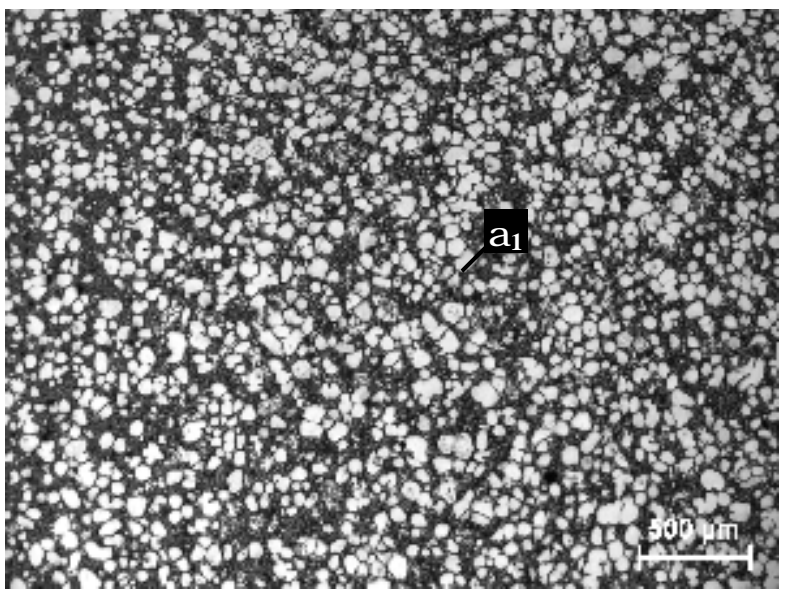

(a)

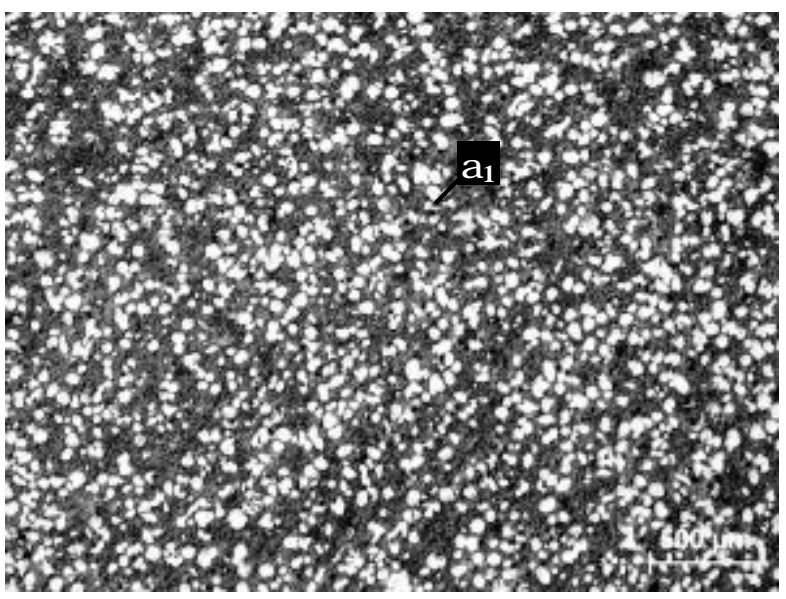

(b)

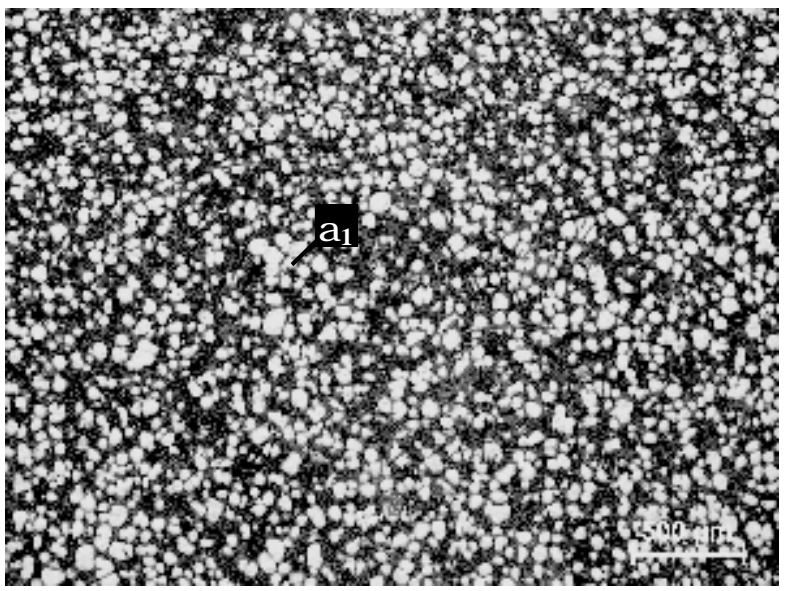

(c)

Fig. II-- Typical microstructures of rheo-diecast AM series alloys: (a) AM50 at $613^{\circ} \mathrm{C}$; (b) $\mathrm{AM} 70$ at $599^{\circ} \mathrm{C}$; (c) $\mathrm{AM} 90$ at $589^{\circ} \mathrm{C}$. The light globular particles (denoted $\alpha_{1}$ ) are formed during primary solidification inside the twin-screw slurry maker; dark regions around the primary $\alpha_{1}$ particle correspond to subsequently solidified structures. 

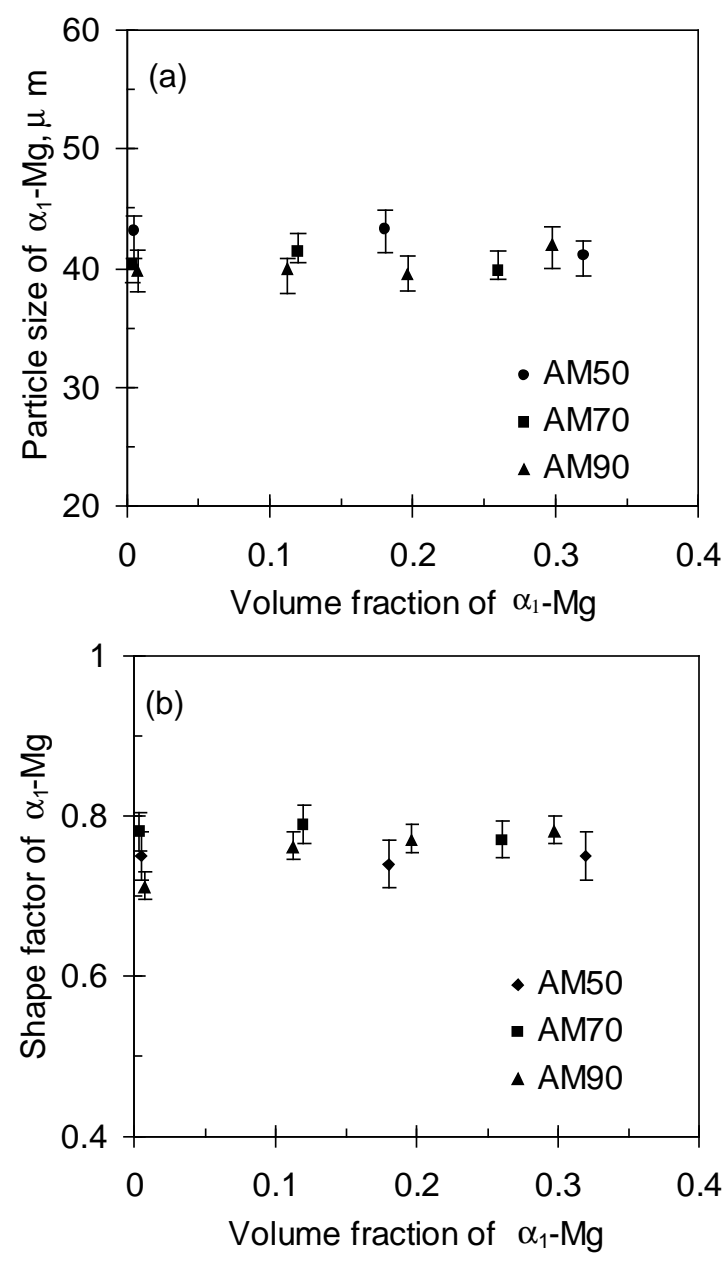

Fig. 3--- Effect of volume fraction on particle size (a) and shape factor (b) of the primary $\alpha_{1}-\mathrm{Mg}$ particles formed during primary solidification inside the twin-screw slurry maker. The error bars indicate the ranges of experimental results obtained.

Table II. EDS analytical results of the primary magnesium phase formed inside the twin-screw slurry maker during rheo-diecasting at the volume fraction $\mathrm{f}_{\mathrm{s}}=0.3$ and the results obtained from CALPHAD calculations under equilibrium conditions.

\begin{tabular}{ccc}
\hline Alloy & $\begin{array}{c}\text { EDS at } \mathrm{f}_{\mathrm{s}}=0.3 \\
\text { wt. } \% A l\end{array}$ & $\begin{array}{c}\text { CALPHAD } \\
\text { wt.\%Al }\end{array}$ \\
\hline AM50 (4.6\%Al) & 1.6 & 1.81 \\
AM70 (7.0\%Al) & 2.4 & 2.42 \\
AM90 (8.8\%Al) & 2.8 & 3.02 \\
\hline
\end{tabular}

CALPHAD for $\alpha_{1}-\mathrm{Mg}$ particles formed during primary solidification. These results, in conjunction with the identified typical flow and solidification behaviour of liquid alloys inside the twin-screw slurry maker ${ }^{[11,12]}$, indicate that the primary solidification in the rheodiecasting process is close to equilibrium solidification.

The secondary solidification occurs as soon as the semisolid slurry is transferred into the shot sleeve, and subsequently injected into the die cavity. The primary phases that are formed in the shot sleeve and the die cavity are denoted $\alpha_{2}-\mathrm{Mg}$ and $\alpha_{3}-\mathrm{Mg}$, respectively. Fig. 4 shows the typical morphology of the $\alpha_{2}-\mathrm{Mg}$ phase in AM series alloys. Unlike the spheroidal morphology of the $\alpha_{1}$-Mg particles, the $\alpha_{2}$-Mg phase was present in the form of dendrites and dendritic fragments due to the absence of shearing. The sizes of the un-fragmented $\alpha_{2}-\mathrm{Mg}$ dendrites are similar to those of the $\alpha_{1}-\mathrm{Mg}$ particles, but those fragmented are smaller. The number of the $\alpha_{2}-\mathrm{Mg}$ phase was higher at a low volume fraction of the $\alpha_{1}-\mathrm{Mg}$ particles than that observed at a high volume fraction of the $\alpha_{1}-\mathrm{Mg}$ particles. Fig. 5 shows the correlation between the volume fraction of the primary $\alpha_{2}-\mathrm{Mg}$ phase and the volume fraction of the primary $\alpha_{1}-\mathrm{Mg}$ phase. In all three alloys, the volume fraction of $\alpha_{2}-\mathrm{Mg}$ was found to decrease significantly with increasing volume fraction of the $\alpha_{1}-\mathrm{Mg}$ particles.

Fig. 6 shows a typical view of the primary Mg phase that was formed in the die cavity during secondary solidification (denoted $\alpha_{3}-\mathrm{Mg}$ ). The $\alpha_{3}-\mathrm{Mg}$ exhibited equiaxed morphology and was smaller in size than both $\alpha_{1^{-}}$ $\mathrm{Mg}$ and $\alpha_{2}-\mathrm{Mg}$. In all three alloys the size of the $\alpha_{3}-\mathrm{Mg}$ phase varied in a narrow range from 6.5 to $8.5 \mu \mathrm{m}$, irrespective of the volume fraction of the $\alpha_{1}-\mathrm{Mg}$ phase and the $\mathrm{Al}$ content in $\mathrm{AM}$ alloys. It is likely that the $\alpha_{3}-\mathrm{Mg}$ phase has included some divorced eutectic Mg phase, but it is difficult to distinguish them.

Fig. 7 shows the distribution of the $\beta-\mathrm{Mg}_{17} \mathrm{Al}_{12}$ phase that was formed in the die cavity during secondary solidification. The $\beta-\mathrm{Mg}_{17} \mathrm{Al}_{12}$ phase was present as a discontinuous network along the grain boundaries of the magnesium phase when observed on polished sections. The micrograph also showed that the primary $\mathrm{Mg}$ phase and the $\beta-\mathrm{Mg}_{17} \mathrm{Al}_{12}$ phase were completely divorced in rheodiecast alloys. As expected, the amount of $\beta-\mathrm{Mg}_{17} \mathrm{Al}_{12}$ increased with increasing $\mathrm{Al}$ content in $\mathrm{AM}$ series alloys (Fig. 8).

\section{$B$ Mechanical properties of as-rheo-diecast AM series alloys}

The mechanical properties of as-rheo-diecast AM series alloys are presented in Table 3. The ultimate tensile strength (UTS) showed little dependence on the Al content in the range from $5 \mathrm{wt} . \%$ to $9 \mathrm{wt} . \%$, and was consistent at about $250 \mathrm{MPa}$. The yield strength demonstrated a conspicuous increase with increasing $\mathrm{Al}$ content. The decrease in elongation with increasing $\mathrm{Al}$ content was expected, but it is very encouraging to find that, even with $9 \mathrm{wt} . \% \mathrm{Al}$ content, the elongation of rheo-diecast AM90 still achieved $(9 \pm 1.2) \%$, which is the near elongation property required for AM60 according to ASTM B 94-94. On top of the excellent ductility, the rheo-diecast AM90 also offered much higher yield strength (150 MPa) than AM60 (125 $\mathrm{MPa}$ ) due to the high $\mathrm{Al}$ content. These results demonstrate that, rheo-diecasting can effectively enhance the ductility of high Al content AM alloys without sacrificing their tensile and yield strengths. In other words, rheo-diecasting provides an attractive processing route for upgrading the alloy specification of AM series alloys via increasing the Al content. This is further supported by the comparison given below.

Table 3 also summarises the tensile mechanical properties of AM series alloys achieved by HPDC, thixocasting and thixomoulding reported in the literature ${ }^{[13-16]}$. Compared to both HPDC and thixocasting, rheo- 

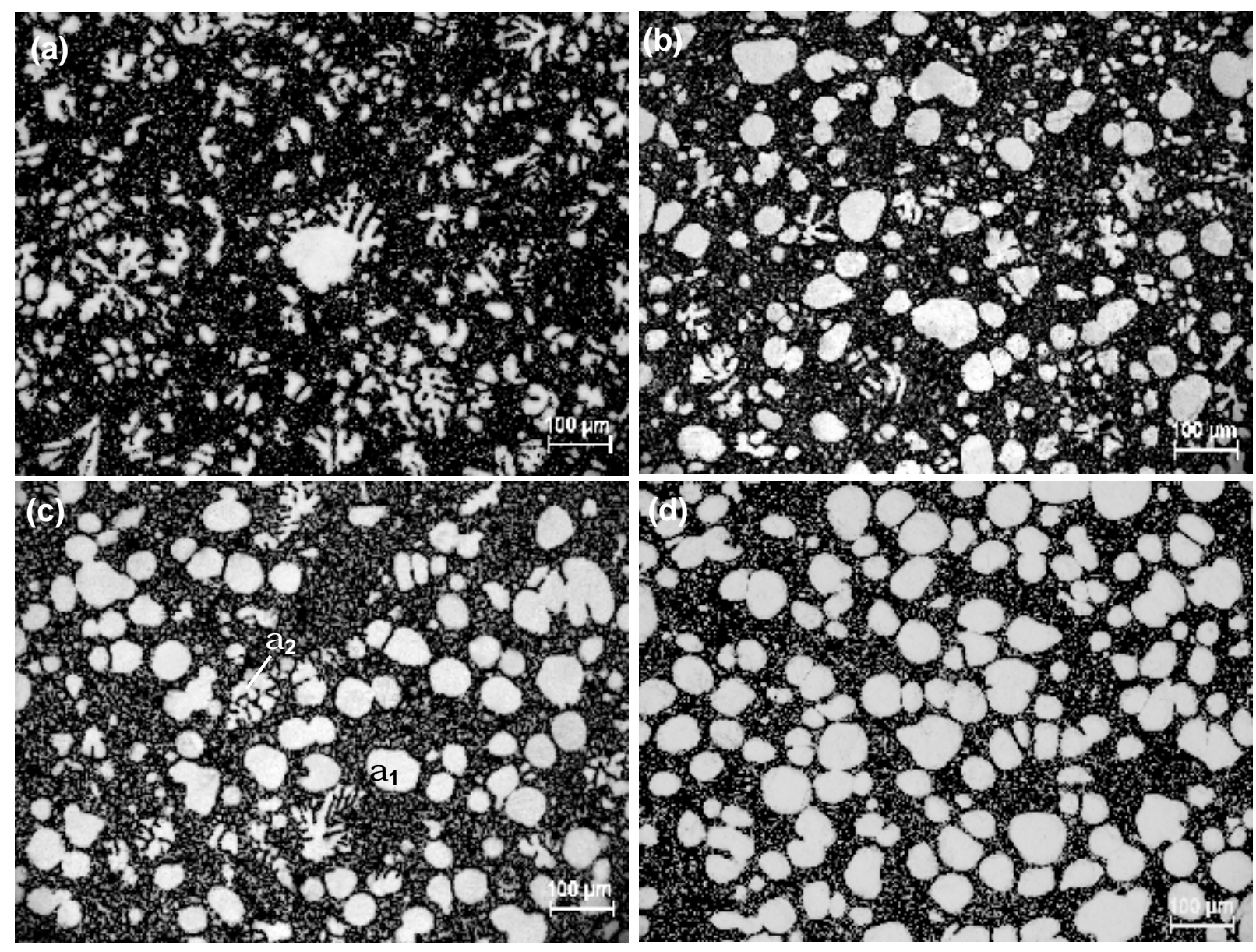

Fig. 4 Optical micrographs showing the typical microstructures of rheo-diecast AM90 alloy; (a) $600^{\circ} \mathrm{C}$; (b) $597^{\circ} \mathrm{C}$; (c) $593^{\circ} \mathrm{C}$; (b) $589^{\circ} \mathrm{C}$. The light globular primary solid particles (denoted $\alpha_{1}$ ) were formed during primary solidification inside the twin-screw slurry maker, and the dendrites and dendritic fragments (denoted $\alpha_{2}$ ) were formed in the shot sleeve during secondary solidification. A detailed view of the dark regions is shown in Figure 6.

diecasting resulted in much improved mechanical properties, especially in elongation. The mechanical properties of rheo-diecast AM series alloys are similar to those achieved by thixomoulding (without solution treatment).

\section{DISCUSSION}

Rheo-diecast AM series alloys demonstrated much improved mechanical properties compared to those achieved by HPDC and thixocasting. Of particular interest is that, even with $9 \mathrm{wt} . \% \mathrm{Al}$ content, rheo-diecast AM90 still exhibited much improved ductility, with the elongation in the range of $(9 \pm 1.2) \%$. These observations are mainly attributed to the high quality semisolid slurry and reduced casting defects in rheo-diecast alloys.

\section{A. Solidification behaviour during rheo-diecasting of AM series alloys}

The primary solidification during rheo-diecasting occurs inside the twin-screw slurry-maker, where both screws have specially designed profiles to achieve co-rotating, self-wiping and fully intermeshing characteristics ${ }^{[5]}$. As a result, the liquid flow inside the twin-screw slurry maker is characterised by high shear rate and high intensity of turbulence. In addition, the intensive shearing produces a constantly renewable contact interface between the cooling melt, the twin screws and the wall of the barrel. These characteristics lead to very efficient cooling, including rapid dissipation of the latent heat released into the melt, and a uniform composition field throughout the melt. Therefore, the bulk melt temperature can quickly and uniformly be reduced to a temperature below the liquidus of the alloy, typically within a few seconds of intensive shearing. The uniformly undercooled melt environment provides a safe shelter for the nuclei that are formed in the melt, and accordingly gives rise to a high nucleus survival rate. On the other hand, it has been found that, turbulent flow favours spheroidal growth by significantly reducing the thickness of both the thermal and the solute diffusion boundary layers at the solid/liquid interface [17]. Furthermore, the uniform melt composition generated by the turbulent flow prevents any significant development of constitutional undercooling at the solid/liquid interface, thus restricting constitutional undercooling playing a noticeable role in growth. The interface is therefore kinetically stabilised under high shear rate and high intensity of turbulence ${ }^{[17]}$. These unique nucleation and growth characteristics result in the formation of fine and spheroidal primary phase particles, as shown in Fig. 2. 


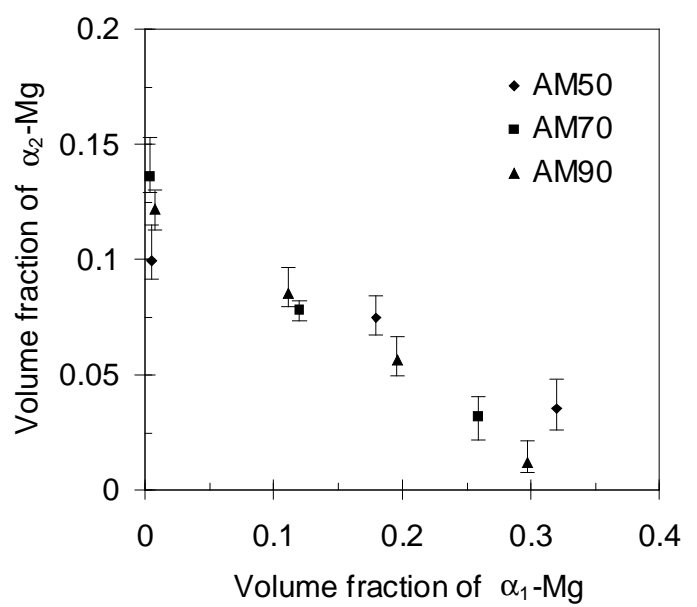

Fig. 5---Correlation between the volume fraction of the primary $\alpha_{2}$ $\mathrm{Mg}$, formed during secondary solidification in the shot sleeve, and the volume fraction of the primary $\alpha_{1}-\mathrm{Mg}$, formed during primary solidification in the twin-screw slurry maker. The error bars indicate the ranges of experimental results obtained.

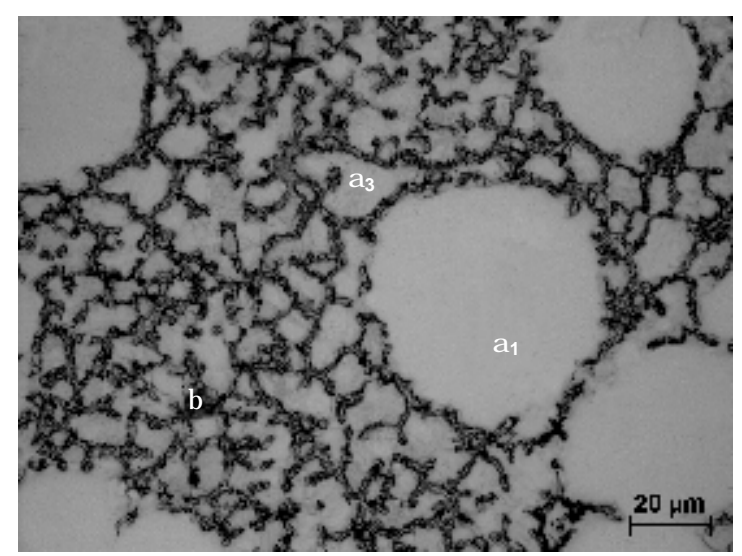

Fig. 6 ---An enlarged view of the dark regions shown in Fig. 4 (d) depicting the primary $\mathrm{Mg}$ phase (denoted $\alpha_{3}$ ) and divorced eutectic structure formed during secondary solidification in the die cavity.

The solidification of the remaining liquid in the semisolid slurry occurs in the shot sleeve and the die cavity at a high cooling rate. It should be noted that the remaining liquid has been subjected to intensive shearing in the twin-screw slurry maker. Therefore it has a uniform temperature (no superheat) in the initial stages of solidification. As such, nucleation tends to occur throughout the remaining liquid in the shot sleeve. In the absence of forced convection, constitutional undercooling gradually develops at the solid/liquid interface. This favours dendritic growth. As shown in Fig. 4 , the amount of the $\alpha_{2}-\mathrm{Mg}$ dendrites is largely dependent on the amount of the $\alpha_{1}-\mathrm{Mg}$ phase present in the semisolid slurry prior to being transferred to the shot sleeve. A large amount of the $\alpha_{1}-\mathrm{Mg}$ phase in the slurry corresponds to the use of a low slurry forming temperature and a small proportion of the remaining liquid. Both contribute to the formation of less $\alpha_{2}-\mathrm{Mg}$ dendrites when the slurry is transferred to the shot sleeve. Although many of the coarse $\alpha_{2}-\mathrm{Mg}$ dendrites

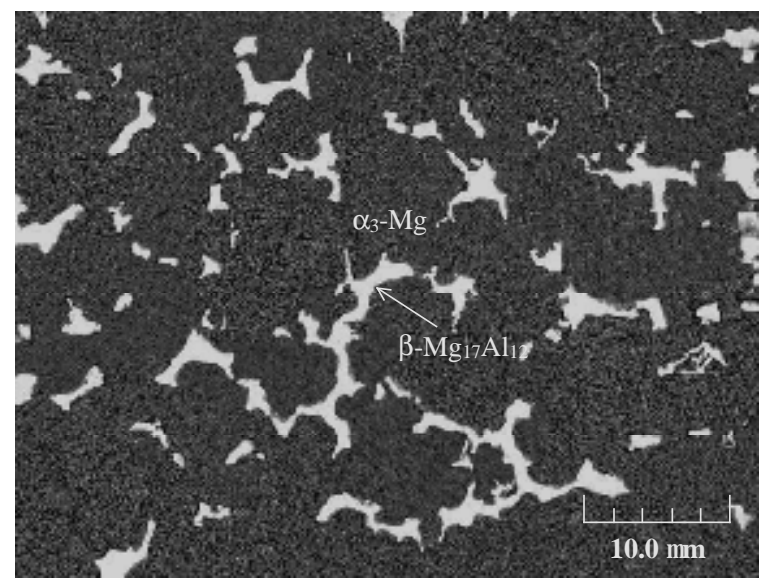

Fig. 7---Backscattered SEM micrograph showing the morphology and distribution of the $\beta-\mathrm{Mg}_{17} \mathrm{Al}_{12}$ phase (in light colour), identified by EDS, in the divorced eutectic structure shown in Fig. 4 (d).

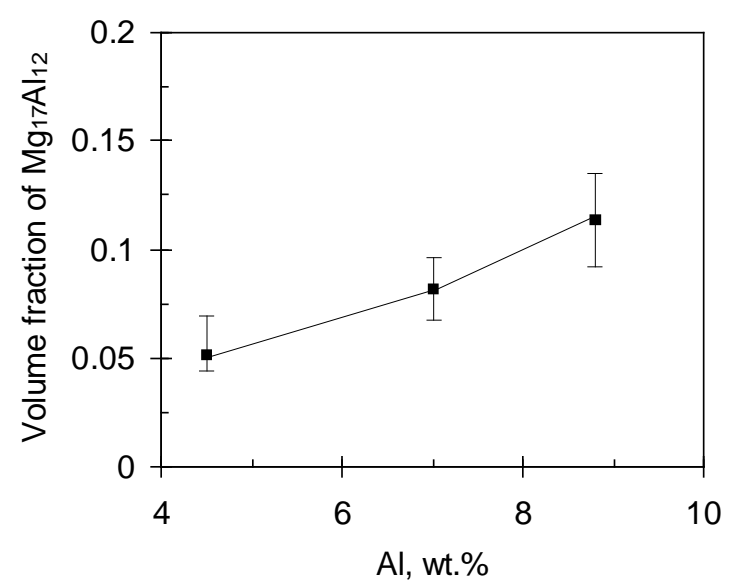

Fig. 8---Volume fraction of the $\beta-\mathrm{Mg}_{17} \mathrm{Al}_{12}$ phase in the remaining liquid of rheo-diecast AM series alloys as a function of the $\mathrm{Al}$ content. The error bars indicate the ranges of experimental results obtained.

that are formed in the shot sleeve could be fragmented when the slurry subsequently passes through the thin gate of the die cavity during high pressure filling (Fig. 4), a large presence of the $\alpha_{2}-\mathrm{Mg}$ dendrites is undesirable. To minimise the formation of the $\alpha_{2}-\mathrm{Mg}$ dendrites, it is important to ensure a large volume fraction of fine and spheroidal $\alpha_{1}-\mathrm{Mg}$ phase in the slurry before it is transferred into the shot sleeve. The unique twin-screw slurry making process used in this work can fulfil this requirement and played a critical role in control of the formation of the $\alpha_{2}$ $\mathrm{Mg}$ dendrites shown in Fig. 4. The secondary solidification carries on in the die cavity after injection. Owing to the high cooling rate (up to $10^{3} \mathrm{~K} / \mathrm{s}$ ), solidification of the remaining liquid resulted in very fine structures, as shown in Figs. 6 and 7.

\section{B. The semisolid processibility of AM series alloys}

The semisolid processibility of a given metal can be assessed from four major aspects: the sensitivity of solid fraction to temperature, the liquidus temperature, the 
Table III. Mechanical properties of AM series alloys collected from the literature and produced by the rheo-diecasting process.

\begin{tabular}{l|l|c|c|c|c|c|c}
\hline Process & Alloy & $\begin{array}{c}\text { Processing } \\
\text { temperature }\end{array}$ & $\begin{array}{c}\text { Elongation } \\
(\%)\end{array}$ & $\begin{array}{c}\text { UTS } \\
(\mathrm{MPa})\end{array}$ & $\begin{array}{c}\text { Yield stress } \\
(\mathrm{MPa})\end{array}$ & $\begin{array}{c}\text { Modulus } \\
(\mathrm{GPa})\end{array}$ & $\begin{array}{c}\text { Reference } \\
\end{array}$ \\
\hline HPDC & AM50 & $660^{\circ} \mathrm{C}$ & 6.7 & 194.8 & 128.7 & 120 & {$[13]$} \\
HPDC & AM50 & $677^{\circ} \mathrm{C}$ & 6.9 & 204 & 124.7 & {$[14]$} \\
HPDC & AM60A & & 13 & 237.0 & 142 & {$[15]$} \\
HPDC & AM60 & $677^{\circ} \mathrm{C}$ & 8.7 & 230 & $108 \pm 6$ & {$[14]$} \\
Thixocasting & AM50 & $614-620^{\circ} \mathrm{C}$ & $7 \pm 0.7$ & $200 \pm 3$ & 140 & {$[6]$} \\
Thixomoulding & AM50 & & 20 & 268.7 & $112.0-146.2$ & {$[16]$} \\
Thixomoulding & AM60 & & $4-11$ & $188.9-268.7$ & 150 & {$[8]$} \\
Thixomoulding & AM60 & & 18.8 & 278.2 & $120 \pm 5$ & $42 \pm 3$ & This study \\
Rheo-diecasting & AM50 & $609-620^{\circ} \mathrm{C}$ & $19.5 \pm 1$ & $240 \pm 9$ & $130 \pm 5$ & $42 \pm 3$ & This study \\
Rheo-diecasting & AM70 & $598-610^{\circ} \mathrm{C}$ & $12 \pm 1.3$ & $240 \pm 10$ & $145 \pm 5$ & $42 \pm 3$ & This study \\
Rheo-diecasting & AM90 & $589-600^{\circ} \mathrm{C}$ & $9 \pm 1.2$ & $243 \pm 10$ &
\end{tabular}

interval between the semisolid processing temperature and the complete solidification temperature, and the morphology of the resulting primary phase particles. As demonstrated previously, the solidification of AM series alloys in the rheo-diecasting process occurs in two distinct stages: the primary solidification inside the twinscrew slurry maker, which is close to an equilibrium process, and the secondary solidification in the shot sleeve and the die cavity at a high cooling rate, which is a non-equilibrium process. These are the processing environments for assessing the semisolid processibility of the rheo-diecast AM alloys.

The sensitivity of solid fraction to temperature, defined as $\left|d f_{s} / d T\right|$, measures the influence of the variation of the semisolid processing temperature on the variation of solid fraction ${ }^{[18]}$. A large $\left|d f_{s} / d T\right|$ alters the rheological property of the alloy and significantly restricts the processing window, hence deteriorating the processibility. Fig. 9 shows the calculated $\left|d f_{s} / d T\right|$ with the solid fraction $\mathrm{f}_{\mathrm{s}}=0.3$ for AM series alloys as a function of the $\mathrm{Al}$ content. As can be seen, $\left|d f_{s} / d T\right|$ decreases conspicuously with increasing $\mathrm{Al}$ content in the range from $3 \% \mathrm{Al}$ to $7 \% \mathrm{Al}$ and gradually after $7 \% \mathrm{Al}$. Apparently, the sensitivity of solid fraction to temperature for high $\mathrm{Al}$ content $\mathrm{AM}$ alloys is much less than that for low $\mathrm{Al}$ content alloys over the SSM processing temperature range. It follows that high $\mathrm{Al}$ content AM alloys are more suitable for semisolid processing.

The liquidus temperature is important in that a lower liquidus temperature means a lower processing temperature for a given solid fraction. Therefore, a longer tool life and easier melt handling are expected as advantages of the semisolid process. According the CALPHAD calculation, $1 \mathrm{wt} . \%$ increase of $\mathrm{Al}$ content in AM series alloys could lead to the decrease of liquidus temperature as much as $5^{\circ} \mathrm{C}$. For the investigated three alloys, the liquidus temperature of AM50, AM70 and AM90 are $620^{\circ} \mathrm{C}, 610^{\circ} \mathrm{C}$ and $600^{\circ} \mathrm{C}$, respectively. Therefore, high Al content AM series alloys are preferred for semisolid processing in this regard.
A large temperature interval between the semisolid processing temperature and the complete solidification temperature $\left(f_{s}=1\right)$, in general, favours the formation of hot tearing during secondary solidification ${ }^{[17]}$. Therefore, an alloy ideal for SSM processing should have a temperature interval that just suffices for subsequent mould filling. Fig. 10 shows the calculated temperature interval, $\mathrm{T}_{\mathrm{fs}=0.3}-\mathrm{T}_{\mathrm{fs}=1}$, for AM alloys as a function of the $\mathrm{Al}$ content, by fixing the semisolid processing temperature corresponding to $\mathrm{f}_{\mathrm{s}}=0.3$. As can be seen, AM series alloys normally have a temperature interval in excess of $150^{\circ} \mathrm{C}$. So, the selection of a high $\mathrm{Al}$ content $\mathrm{AM}$ alloy for semisolid processing will give a narrower temperature interval, provided that the ductility of the semisolid processed high Al content AM alloy is still satisfied.

The morphology of the $\alpha_{1}-\mathrm{Mg}$ particles alters the processibility by affecting the pseudoplastic and rheological performance of the semisolid slurry. It has been well established that neither dendritic forms of particles nor rosette-like particles with entrapped liquid are satisfying, and only fine and spheroidal particles can deliver satisfactory pseudoplastic and rheological performance ${ }^{[19]}$, and therefore good semisolid

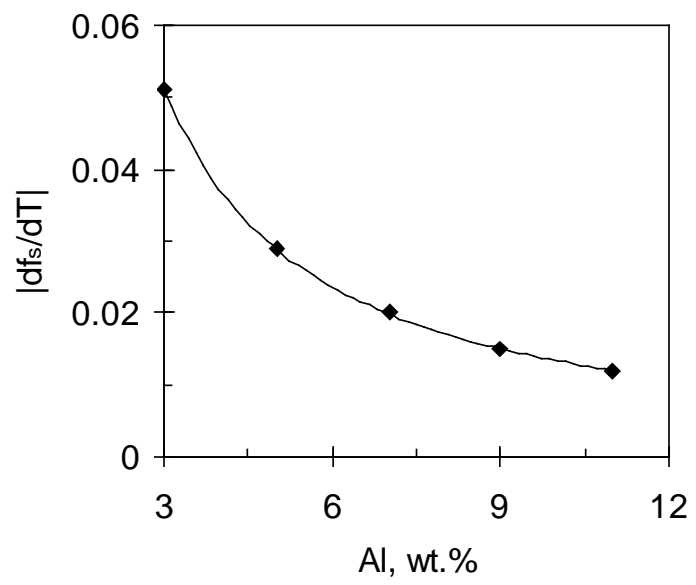

Fig. 9---Calculated $\left|d f_{s} / d T\right|$ at $f_{s}=0.3$ for $A M$ series alloys as a function of the $\mathrm{Al}$ content using the Scheil model in the CALPHAD approach. 


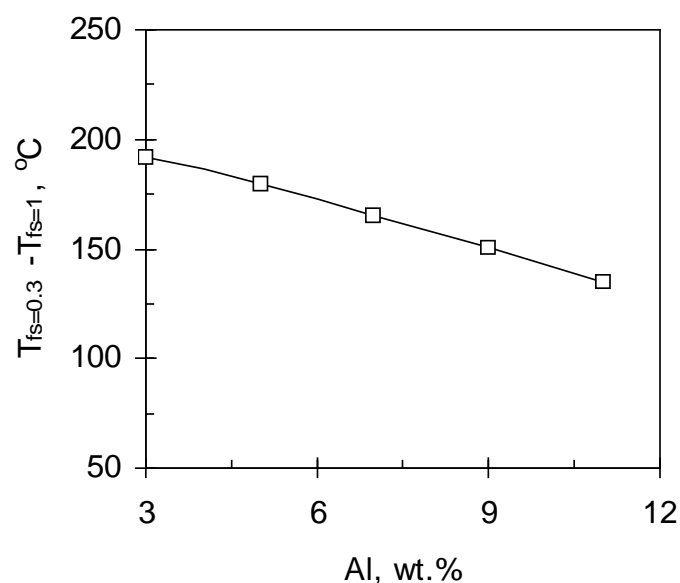

Fig. 10---Calculated temperatures intervals between the semisolid processing temperature corresponding to $\mathrm{f}_{\mathrm{s}}=0.3$ and the complete solidification temperature $\left(\mathrm{f}_{\mathrm{s}}=1\right)$ for $\mathrm{AM}$ alloys using the Scheil model in the CALPHAD approach.

processibility. The unique twin-screw melt shearing approach used in the rheo-diecasting process can consistently deliver high quality semisolid slurry containing fine and spheroidal particles, as has been shown in both Fig. 2 and Fig. 4(d). This imparts good semisolid processibility to AM series alloys.

These assessments clearly point to the suggestion that the use of a high $\mathrm{Al}$ content facilitates semisolid processing of AM series alloys. An additional advantage is that, when containing more than $6 \mathrm{wt} . \% \mathrm{Al}$, the alloys become heat treatable ${ }^{[6]}$. This can be exploited to further improve their strength and ductility.

\section{Effect of the Al content on the mechanical properties of as-rheo-diecast AM series alloys}

The $\mathrm{Al}$ content in $\mathrm{AM}$ series alloys is usually controlled below 6wt.\% for HPDC. This is because increasing the $\mathrm{Al}$ content will increase the amount of the $\beta-\mathrm{Mg}_{17} \mathrm{Al}_{12}$ phase, which deteriorates the ductility of AM series alloys, as tensile fracture always initiates by the cracking of the $\beta-\mathrm{Mg}_{17} \mathrm{Al}_{12}$ phase ${ }^{[20]}$. The results obtained from this study (Table 3 ) indicate that rheodiecasting can obviously enhance the ductility of high $\mathrm{Al}$ content AM alloys. This is mainly attributed to the unique microstructure and the reduced casting defects achieved by rheo-diecasting.

Aluminium is present in two major forms in AM series alloys: by solid solution in the $\alpha-\mathrm{Mg}$ phase and by combination with $\mathrm{Mg}$ to form the $\beta-\mathrm{Mg}_{17} \mathrm{Al}_{12}$ phase. In a typical rheo-diecasting process, the $\alpha_{1}-\mathrm{Mg}$ phase contains much less $\mathrm{Al}$ than both $\alpha_{2}-\mathrm{Mg}$ and $\alpha_{3}-\mathrm{Mg}$. Quantitative EDS analyses confirmed that, on average, the $\mathrm{Al}$ content in the $\alpha_{3}-\mathrm{Mg}$ phase is at least $50 \%$ higher than that in the $\alpha_{1}-\mathrm{Mg}$ phase. Therefore, the uniformly distributed fine and spheroidal $\alpha_{1}-\mathrm{Mg}$ phase, as the most ductile constituent in a rheo-diecast AM alloy, plays an important role of counterbalancing the negative effects of the $\beta-\mathrm{Mg}_{17} \mathrm{Al}_{12}$. Another positive aspect is that, because of the proved rheological performance arising from the fine and spheroidal $\alpha_{1}-\mathrm{Mg}$ particles, rheo- diecasting allows use of a high solid fraction of the $\alpha_{1}-\mathrm{Mg}$ phase. This helps minimise the formation of the undesirable dendritic $\alpha_{2}-\mathrm{Mg}$ phase in the shot sleeve of the HPDC machine. Furthermore, the uniformly distributed spheroidal $\alpha_{1}-\mathrm{Mg}$ phase reduces the detrimental effects of the network of the $\beta-\mathrm{Mg}_{17} \mathrm{Al}_{12}$ phase on the ductility of a rheo-diecast alloy. As can be seen from Fig. 4 (d) and Fig. 6 , where Fig. 6 is an enlarged view of the dark regions shown in Fig. 4 (d), the network of the $\beta-\mathrm{Mg}_{17} \mathrm{Al}_{12}$ phase in the rheo-diecast AM90 alloy is consistently interrupted by those spheroidal and ductile $\alpha_{1}-\mathrm{Mg}$ particles. This reduces the obstacle of deformation and the harmfulness of the network on the ductility, compared to the uninterrupted network of the $\beta-\mathrm{Mg}_{17} \mathrm{Al}_{12}$ phase in the microstructure processed by HPDC, as shown in Fig. 11. In addition, it has been found that the RDC process can effectively reduce the occurrence of hot tearing and porosity due to the decreased casting temperature, increased viscosity, and elimination of the coarse dendritic structures with replacement by spheroidal particles ${ }^{[21]}$. This improves the integrity and contributes favourably to the enhanced mechanical properties._The overall effect is that high $\mathrm{Al}$ content AM series alloys still demonstrated ductility after rheo-diecasting. So, it is the unique microstructure achieved by rheo-diecasting that ensures the ductility of high $\mathrm{Al}$ content $\mathrm{AM}$ series alloys such as AM90.

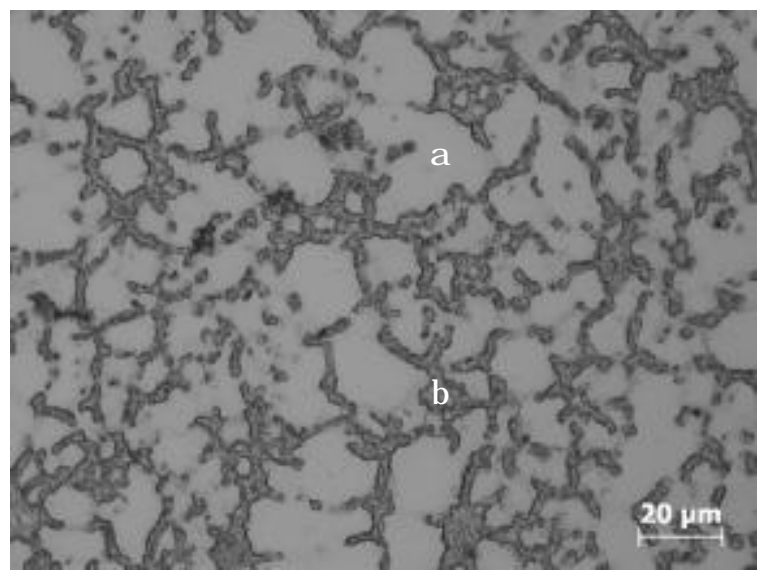

Fig. 11--- Optical micrograph showing a typical view of the divorced eutectic structure in an AM90 alloy sample processed by HPDC, where the $\beta-\mathrm{Mg}_{17} \mathrm{Al}_{12}$ is present as a network-like structure when observed on a polished section.

\section{CONCLUSIONS}

The AM series alloys are suitable for rheo-diecasting but high $\mathrm{Al}$ content $\mathrm{AM}$ series alloys are preferred to low $\mathrm{Al}$ content alloys, because of the lower sensitivity of solid fraction to temperature, the lower liquidus temperature, and the smaller temperature interval between the semisolid processing temperature and the complete solidification temperature.

During rheo-diecasting the primary solidification occurs inside the twin-screw slurry maker under intensive melt shearing, which results in spheroidal primary magnesium particles at the order of $40 \mu \mathrm{m}$ in size with a shape factor around 0.75 . The secondary solidification in the shot sleeve gives rise to the dendritic forms of primary magnesium phase, and that in the die cavity produces equiaxed primary 
magnesium particles in the size range of 6.5 to $8.5 \mu \mathrm{m}$, and the divorced eutectic structure.

Owing to the formation of the numerous spheroidal primary magnesium particles in the twin-screw slurry maker during rheo-diecasting, the network of the $\beta$ $\mathrm{Mg}_{17} \mathrm{Al}_{12}$ phase in rheo-diecast AM alloys is consistently interrupted by these particles. Such a unique microstructure reduces the obstacle of deformation and the harmfulness of the network on the ductility, and improves the ductility of the RDC processed AM series alloys.

Rheo-diecasting provides an attractive processing route for upgrading the alloy specification of AM series alloys by increasing the $\mathrm{Al}$ content while ensuring ductility.

\section{ACKNOWLEDGMENTS}

The financial support from EPSRC is gratefully acknowledged. The authors wish to thank Dr. Z. Zhen for his valuable help with all casting work, Dr. Y. Liu for help with CALPHAD calculation, and Dr. Y. Wang for performing the SEM analysis. Magnesium Elektron Limited is acknowledged for the provision of the raw materials.

\section{REFERENCES}

1. M. C. Flemings: Proceedings of $6^{\text {th }}$ International Conference on Semi-solid Processing of Alloys and Composites (eds. G. L. Chiarmetta, M. Rosso), Turin, Sept. 27-29, 2000, pp.11-14.

2. Z. Fan: Inter Mater Rev, 2002, vol. 47, pp.49-85.

3. H.V. Atkinson: Progress in Mater Sci, 2005, vol. 50, pp.341-412.

4. Z. Fan, S. Ji and M. J. Bevis: UK Patent GB 2354
471 A.

5. S. Ji, Z. Fan, M. J. Bevis: Mater Sci Eng A, 2001, vol. A299, pp.210-217.

6. M. M. Avedessian, H. Baker: Magnesium and Magnesium alloys, ASM International, Materials Park, OH, 1999, pp.14-16; 90-92.

7. Z. Koren, H. Rosenson, E. M. Gutman, YaB. Unigovski, A. Eliezer: J. Light Metals, 2002, vol. 2, pp.81-87.

8. F. Czerwinski: Acta Mater. 2004, vol. 52, pp.5057-5069.

9. F. Czerwinski: Acta Mater. 2005, vol. 53, pp.1973-1984.

10. Z. Fan, S. Ji, G. Liu: Materials Science Forum, 2005, vol. 488-489, pp.405-416.

11. Z. Fan, G. Liu: Acta Mater. 2005, vol. 53, pp.43454357.

12. S. Ji, Z. Fan: Metall Trans, A, 2002, vol. 33A(11), pp. 3511-3520.

13. R. M. Wang, A. Elizer, E. M. Gutman: Mater Sci Eng A, 2003, vol. A355, pp.201-207.

14. G. Chadha, J. E. Allison, J. W. Jones: Magnesium Technology 2004, (ed. A. A. Luo), TMS, 2004, pp.181-186.

15. A. M. Gokhale, G. R. Patel: Magnesium Technology 2001, (ed. J. Hryn), TMS, 2001, pp.195-199.

16. F. Czerwinski, A. Zielinska-Lipiec, P. J. Pinet, J. Overbeeke: Acta Materialia, 2001, vol.49, pp.12251235.

17. A. Das, S. Ji, Z. Fan: Acta Materialia, 2002, vol. 50, pp. 4571-4585.

18. Y. Q. Liu, A. Das, Z. Fan: Mater. Sci. Tech., 2004, vol. 20, pp.35-41.

19. J.Y. Chen, Z. Fan: Mater. Sci. Tech., 2002, vol.18, pp.237-258.

20. G. L. Dunlop, W. P. Sequeira, M. S. Dargusch, G. Song, A. Atrens, T. Kittel, D. H. StJohn, A. K. Dahle, M. Murray: Proceedings of the $55^{\text {th }}$ Meeting of International Magnesium Association, 1998, pp.68-73.

21. Z. Zhen, Ma Qian, S. Ji, Z. Fan: Scripta Mater. 2006, vol. 53, 207-211. 